\title{
The Evaluation of Harm and Purity Transgressions in Africans: A Paradigmatic Replication of Rottman and Young (2019)
}

Adeyemi Adetula ${ }^{1}$, Patrick S. Forscher ${ }^{1,2}$, Dana Basnight-Brown ${ }^{3}$, Jordan Wagge ${ }^{4}$, Takondwa Namalima ${ }^{5}$, Frank Kaphesi ${ }^{5}$, Wickson Kaliyapa ${ }^{5}$, Kennedy Mulungu ${ }^{5}$, Walusungu Silungwe ${ }^{5}$, Chamkat Polycarp ${ }^{6}$, Winfrida Malingumu ${ }^{7}$, Soufian Azouaghe ${ }^{8}$, Ebaa Alsayed ${ }^{9}$, Izuchukwu Ndukaihe $^{10}$, Milton Kalongonda ${ }^{5}$, Uba Donald Dennis ${ }^{25}$, Alert Dzuka ${ }^{5}$, Abdelilah Charyate $^{12}$, Gabriel Agboola Adetula ${ }^{11}$, Chisom Esther Ogbonnaya ${ }^{10}$, Mesay Shanka ${ }^{13}$, Nsi Eze $^{14}$, Oko Enworo ${ }^{15}$, Nwadiogo Chisom Arinze ${ }^{10}$, Zione Gold ${ }^{5}$, Saheed Abolade ${ }^{16}$, Olawu Shumiye $^{6}$, Jaime Nhaguilunguana ${ }^{17}$, Moses Agbede ${ }^{11}$, Ayomitan Olotu ${ }^{15}$, Dércio Armando ${ }^{19}$, Ogochukwu Ugwuneke ${ }^{20}$, Afolashade Onunkun ${ }^{21}$, Yusuf Dinala ${ }^{5}$, Mutsai Bakali ${ }^{5}$, Precious $\mathrm{Ike}^{22}$, Dorcas Ovurevu ${ }^{23}$, Dennis Kibuga ${ }^{24}$, Richard $\mathrm{Adu}^{15}$, Maximilian Primbs ${ }^{26}$, Hans IJzerman ${ }^{1,27}$

Affiliations:

${ }^{1}$ LIP/PC2S, Université Grenoble Alpes

${ }^{2}$ Busara Center for Behavioral Economics

${ }^{3}$ United States International University-Africa

${ }^{4}$ Avila University

${ }^{5}$ Kamuzu University of Health Sciences

${ }^{6}$ University of Jos

${ }^{7}$ The Open University of Tanzania

${ }^{8}$ Mohammed V University in Rabat

${ }^{9}$ The American University In Cairo

${ }^{10}$ Alex Ekwueme Federal University Ndufu-Alike

${ }^{11}$ Adekunle Ajasin University Akungba-Akoko

${ }^{12}$ Ibn Tofail University (UIT)

${ }^{13}$ Université Internationale de Rabat

${ }^{14}$ Alex Ekwueme Federal University Teaching Hospital Abakaliki

${ }^{15}$ University of Pretoria

${ }^{16}$ Southwestern University

${ }^{17}$ Enko Sekeleka International School

${ }^{18}$ University of Ibadan

${ }^{19}$ Manipal Academy of Higher Education

${ }^{20}$ University of Nigeria, Nsukka

${ }^{21}$ Federal University of Technology Akure

${ }^{22}$ Nnamdi Azikiwe University Awka

${ }^{23}$ Baze University

${ }^{24}$ Research, Community and Organizational Development Associates

${ }^{25}$ Madonna University Nigeria

${ }^{26}$ Radboud University Nijmegen

${ }^{27}$ Institut Universitaire de France (IUF) 


\section{Author Note:}

We wrote this report in past tense to reduce the chance for errors, though we are yet to conduct some of these activities.

\section{Authors contribution statement}

A. Adetula, P. S. Forscher, D. Basnight-Brown, and H. IJzerman conceptualized and developed the research project and led the draft of the manuscript. J. R. Wagge provided critical feedback on the project, provided guidance, and helped manage the project as the current CREP director. She also led the creation of the research materials such as the CREP training videos. P. S. Forscher led the data analysis and interpretation of results, reanalyzed the original data, helped calculate the power analysis, and provided critical reviews and advice. M. Primbs led the translation and cultural adaptations of the questionnaire. D. Basnight-Brown led the IRB processing and ethical consideration. All other authors contributed to data collection, reviewing of manuscript, coordination of the site, and translation and adaptation of the questionnaires. Exact contributions of each of these authors will be specified at the end of data collection. 


\begin{abstract}
Improving the generalizability of psychology findings to a culture requires sampling participants in that culture. Yet psychology studies rarely sample from African populations, even though it represents $17 \%$ of the overall world population. This study aimed to conduct an African-led replication study to test whether Rottman and Young's "mere-trace" hypothesis of moral reasoning (that people are more sensitive to the dosage of harm-based transgressions than purity transgressions) extends to several African communities. We used a training method developed by the Collaborative Replication and Education Project (CREP) to support and train 23 African collaborators. During this process, we conducted a paradigmatic replication of Rottman's and Young's test of the mere trace hypothesis in Egypt, Malawi, Morocco, Mozambique, Nigeria, South Africa, and Tanzania. [We did not find/We found] evidence for the main interaction effect (bdomain $x$ dose $=\mathrm{xxx}$ ) of transgression severity on the moral wrongness judgment of impure and harmful violations. [We did/ However, we did not] replicate Rottman and Young's findings among Africans. This project helped improve the research capacity of our participating African sites and will support other researchers in collaborating with African scholars.
\end{abstract}




\section{The Evaluation of Harm and Purity Transgressions in Africans:}

\section{A Paradigmatic Replication of Rottman and Young (2019)}

In recent years, psychological scientists have successfully pushed for greater rigor throughout the research lifecycle, especially better replicability (Munafò et al., 2017). Yet, while scholars have had some success improving replicability (Protzko et al., 2020), progress toward better generalizability has lagged. In a recent audit of top psychology journals, fully $82 \%$ of both first authors and research samples were from North America and Europe (Thalmayer et al., 2020), even though these world regions comprise $17 \%$ of the global population (Roser, 2013). This means that we cannot know whether the theories generated from North America and Europe apply outside of these world regions. This is especially true of Africa; despite comprising $18 \%$ of the global population, Africa contributed less than $1 \%$ of first-authors and samples in the above audit (Thalmayer et al., 2020).

One potential reason for the lack of African researchers and participants is that psychology research is "nascent" in most African countries (Nsamenang, 2007), a state of affairs that reflects a continent starved of the resources to compete with its contemporaries (UNESCO, 2021). This nascent status means that little capacity to conduct psychology research in Africa is available (Adetula et al., 2021). A first step to address this challenge is to conduct research in which the methods are well developed, as is the case of replication studies while involving researchers from the target populations. In the present project, we conducted a paradigmatic replication (Vohs et al., 2021) of studies of purity- and harm-based moral judgments from Rottman and Young (2019) in [xxxx] African countries. We used a training model developed by the Collaborative Replications and Education Project (CREP), a platform that emphasizes "big team" replication studies to teach cutting-edge research practices (Wagge, Baciu et al., 2019; Wagge, Brandt et al., 2019) to test the generalizability to Africans on a set of findings on moral reasoning about harm and purity transgressions. 


\section{The Collaborative Replication and Education Project Model}

This project used a model developed by the Collaborative Replication and Education Project (CREP). We chose the CREP model because it is a highly structured model for training in cutting-edge research methods and gives users many opportunities to provide feedback to improve the model. The latter is particularly useful when deployed in new environments. The CREP model was originally developed for new trainees with little to no prior research experience in scientific psychology (see Wagge, Brandt, et al., 2019).

The trainees organize their project and its materials via a page on the Open Science Framework (OSF). In the first stage of organizing their project, trainees create a copy of the general CREP project by "forking" it. The trainees organize their study materials by filling out each component in the forked project. This includes the full study materials, including any surveys, protocols, and pictures of the materials, a videotape of an experimenter completing the procedure, ethics approval, and a written preregistration. The project is then reviewed for accuracy by an instructor and submits the page to the CREP board. The CREP board conducts a second set of reviews and gives the trainees feedback about the structure and accuracy of the OSF page.

After the pre-data-collection review process is complete, the trainees pre-register the study by creating a frozen copy of the complete OSF project and then proceed to data collection. Under the traditional CREP model, each trainee recruits at least 100 participants, whose responses are stored in a dataset that they themselves manage. Each trainee documents their dataset with a codebook, and creates their own data analysis script. These materials are uploaded to their project pages, which are submitted to the CREP board for another round of review. Once the post-data-collection reviews are complete, the trainees receive a certificate of completion from the CREP board. The full CREP project consists of a meta-analytic synthesis of the results reported by each trainee. 
We adapted this model to help build research capacity among our collaborating researchers. Instead of meta-analyzing the effect sizes, we decided to manage a single dataset centrally, both to allow for the use of Linear Mixed Effects Models on the central dataset in an effort to minimize errors in the merging of the dataset and in the analysis pipeline. To gain the benefits of the CREP training, our collaborators completed the other elements of the CREP procedure. We provided materials - like methods, instruments, or training materials needed for the present study. To ensure the studies were feasible, we decided that researchers could participate if they had basic infrastructure and required resources such as access to a lab and research facilities, space for in-person survey, reliable internet service, and internet connecting devices.

\section{Preparatory Work}

For each site, there was at least one coordinating researcher, who was responsible for coordinating all local research activities, including providing study documentation, translating and adapting instruments, and collecting data (see Supplementary Table 2 at: https://osf.io/d73hf/ for an overview of sites). As most of our collaborators are not yet familiar with the CREP model, we first trained 15 of our participating collaborators in open science and the CREP model using a series of four CREP training videos subtitled in six African languages that described from start to finish how to conduct a CREP project. To ensure that researchers that joined later had access to this training, we made the training materials and reports of the training available at $\underline{\mathrm{https}: / / \text { osf.io/b2pz6/ }}$ and $\underline{\mathrm{https}: / / o s f . i o / 8 \mathrm{akz} 5 /}$. Then, we assessed whether interested sites had the needed facilities and resources to be able to successfully conduct a CREP study locally. The assessment report is available at $\underline{\text { https://osf.io/gds } 7 \mathrm{~b} / .}$.

In order to select which studies to replicate, we engaged in a 3-stage study selection procedure. In the first stage, we nominated 26 articles published in Psychological Science 
between 2015 - 2020 using a set criteria of studies that: sampled no or few Africans, were preregistered, reported a $p$-value $<.01$, and that we considered moderately feasible, applicable, relevant, and ethically acceptable in Africa. In the second stage, we shortlisted three out of eight top-ranked articles we considered to meet these criteria. In the third stage, 18 African researchers assessed the studies reported in these articles for feasibility, adaptability, applicability, interest and relevance in their local context, and lastly, were asked to pick preferred studies to replicate. Based on their responses, we selected Studies 2 and 3 of Rottman's and Young's (2019) article "Specks of dirt and tons of pain: Dosage distinguishes impurity from harm”. The study selection materials and the study assessment report are available at https://osf.io/vwxu3/.

\section{Main Study: Paradigmatic Replication of Rottman and Young}

In their research, Rottman and Young (2019) investigated whether people's moral judgments about purity violations are less sensitive to increases in frequency and severity than moral judgments about harm. Harm violation can be described as a physical/bodily harmful infraction directed toward a target (e.g., stoning a puppy or poking oneself with a needle), while purity violations involve someone acting or engaging in an impure, nonphysical/non-bodily harmful acts (e.g., throwing feces at a dog or licking one's blood; see Horberg et al., 2009; Rozin et al., 1999).

Rottman and Young (2019) proposed the "mere-trace hypothesis" such that moral evaluation of purity-based and harm-based violations differ in their dependence on the severity of the violation. According to this mere-trace hypothesis, the moral wrongness of impure acts (e.g., incest; see Chakroff et al., 2013 and Haidt, 2007) shouldn’t matter; if they occur, they are judged as wrong, regardless of whether the "dosage" of the violation was low (a less severe violation) or high (a more severe violation). In contrast, the moral wrongness of acts that are harmful rather than impure should be more sensitive to dosage. Harmful acts 
(e.g., assault) should be judged as more wrong if they have a higher "dosage" (i.e., if the violation is more severe). In Rottman and Young's Study 2, they presented participants with 8 harm-based violations and 8 purity-based violations. Each violation had a "low dose" version (i.e., the violation was either infrequent or mild; "A person throws a small rock at a farm animal") and a "high dose" version (i.e., the violation was either more frequent or severe; "A person throws a large rock at a farm animal"). Study 3 used 16 new violations, 8 harm-based and 8 purity-based, each of which once again had "low dose" and "high dose" versions. In each study, participants judged how wrong, harmful, and impure each violation was using a 0 to 100 slider scale. Across the two studies, participants judged purity-based violations to be similarly wrong regardless of dosage. However, they judged high-dose harm-based violations to be more wrong than low-dose harm-based violations.

We were able to reproduce Rottman and Young's (2019) findings using their dataset and analysis scripts available at https://osf.io/zxp9k/. However, after reviewing Rottman's and Young's statistical models, we believe that they are implausible assumptions that produce inflated nominal rates of false positives (Judd et al., 2012) by omitting by-person random slopes for domain, dose, and their interaction, as well as by-item random slopes for dose. We therefore reanalyzed the data and accounted for random slopes. This reanalysis showed that the $p$-values of the focal domain by dose interaction were larger than reported in the original studies. In the case of Study 3, the focal $p$-value was no longer significant. Because the effect in one of the studies was no longer robust with what we regarded as a more accurate statistical model, we therefore examined the robustness of the evidence across all studies. After extracting each coefficient in a random slopes model and synthesizing it using random effects meta-analysis, we obtained a meta-analytic estimate of $-9.6,95 \%$ CI [-14.3, -4.9]. This suggests that, although the evidence within studies is not as robust as originally reported, the 
evidence across studies is robust. The full report of the reanalysis and meta analysis are available at https://osf.io/2skhq/.

Our re-analysis revealed that the original design of Rottman and Young underestimates the amount of by-item variability. In the presence of by-item variability, the number of items places a hard upper limit on the amount of statistical power a study can achieve (Westfall, Kenny, \& Judd, 2014). We therefore shifted to a "paradigmatic replication" approach involving modifying an original (to-be-replicated) study's method, design, or materials, and potentially correcting flaws in the methods, design, or materials, so that the new study is diagnostic of the original study's claims as our best-faith effort interpretation of the original studies (see Vohs et al., 2021). Instead of a close replication of Rottman and Young's Study 2 or Study 3, which involves faithfully following the original study procedure and method as close as possible (see Brandt et al., 2014; Schmidt, 2009), we created a new design with additional stimuli to increase statistical power. This modified design combines the items from both Study 2 and Study 3, for a total of 32 items (16 harm-based violations, 16 purity-based). In addition, instead of using the same statistical model as Rottman and Young, we used one that includes random slopes for by-participants for domain, dose, and their interaction, for by-item for dose, as well as random slopes for by-site for domain, dose, and their interaction, which is not a factor in Rottman's and Young's design.

Even if Rottman's and Young's findings could be robust and replicable among US samples, the findings may not generalize to other countries. To date, only a few studies on purity-based violations have been conducted in Africa. Stankov and Lee (2016) provide a notable exception in their study of social attitudes and values across 33 countries, including participants from Egypt, Ethiopia, Kenya, Morocco, and Tanzania. They conducted exploratory and confirmatory factor analyses of 20 social attitudes and values measures. They found that factors of morality, religiosity, and nastiness cut across these countries' cultures. 
The psychological literature on moral theorizing rarely provides insight into African morality, including how Africans think about harm and purity (see also Wareham, 2017). The extent to which moral norms, in relation to harm and purity, are universal or particular is thus mostly unknown. Hence we are agnostic about studying how and whether Rottman and Young's effects apply to the African populations we study. The main goal, therefore, is to explore moral concerns in a variety of African populations. In the current project, we collaborate with African researchers to test the generalizability of Rottman's and Young's (2019) findings in African populations. We will use the CREP model to ensure that the research we conduct is of comparable quality across sites.

\section{Method}

\section{Power Analysis}

We conducted a simulated-based power analysis using the simr package (Green \& MacLeod, 2016) to determine the sample size required to test the effect at $90 \%$ power. We assumed a moderate level of variance of 25 in the by-site random intercepts and slopes and that each site would recruit 100 participants in line with the CREP requirement. Only when we combined the Study 2 and Study 3 items to increase the number of items to 32 for a simulation, did we detect $90 \%$ power to test the focal dosage by domain interaction if we were to run the study at 10 sites (see Supplementary Figure 1 at https://osf.io/bjhv6/, along with the full power analysis report). Moreover, we over recruited by $15 \%$ to allow for exclusion. Therefore, we decided to recruit at least 10 sites, each of whom will recruit at least 115 participants, for a minimum of 1150 participants.

\section{Participants}

We recruited a total of $\operatorname{xxxx}$ [minimum 1150] participants from xx sites [at least 10] in xx African countries [Egypt, Malawi, Morocco, Mozambique, Nigeria, Tanzania, South Africa, and $\mathrm{xxx}$ ] for the study. In the Rottman and Young studies, participants were recruited 
via MTurk. However, because online survey tools are not readily available in some African countries and some participants did not have access to stable internet or devices such as smartphones or computers, sites were allowed to decide their own participant recruitment approach. In one approach, sites recruited participants via online social media platforms (e.g. Whatsapp, Facebook, Twitter) by soliciting participation and sharing the Qualtrics survey link with potential participants to take the survey. In another approach, coordinators set-up a workroom and device(s) connected to the internet, where participants without access or devices to connect to the internet could take the survey online.

\section{Materials}

We combined all 32 items from Rottman's and Young's Study 2 (16 items) and Study 3 (16 items); see Table 1. Half the items present harm-based violations, while the other present purity-based violations. An "item" consists of a single violation that has a low dose and a high dose version. 


\section{Harm violation}

A person starves a goat [once/frequently]

A person bullies a colleague [every so often/every week].

A person [occasionally/regularly] holds meetings in a room with high asbestos levels.

A person purposely knocks a sibling unconscious on [one occasion/many occasions].

A person throws a [small/large] rock at a farm animal.

A person punches [another person/20 other people].

A person angrily gives somebody a

[tiny/huge] bruise on their leg.

A person kills [two/50] deer while hunting.

Linda pushes a thumbtack [one

millimeter/one centimeter] into the skin of her classmate's back.

Chris pricks his colleague with a knife and draws [a single drop/a teaspoon] of blood.

Sarah prescribes her patients a medication that contains a $[0.001 \% / 0.1 \%]$ trace of mercury.

Daniel puts his sister in a chokehold for [a split second/thirty seconds].

Mary secretly puts [a gram of/a quarter-pound of] hot sauce into a restaurant's ketchup bottle.

John takes his pet fish out of its bowl, depriving it of water, for [an instant/a minute].

Jenny sprays [one particle/a fluid ounce] of a hazardous chemical into a residential area.

Adam catches [a single ladybug/10 ladybugs] and poisons [it/them].

\section{Purity violation}

A person has intercourse with a goat [once/frequently].

A person uses heroin [every so often/every week].

A person [occasionally/regularly] masturbates with a chicken carcass.

A person has protected sex with a sibling on [one occasion/many occasions].

A person eats a [small/large] amount of flesh from a dead person.

A person inappropriately touches [a corpse $/ 20$ corpses].

A person builds a [tiny/huge] house on ground that is considered sacred.

A person draws graffiti on [two/50] churches.

Alice consumes

a [one-millimeter/one-centimeter] thick piece of flesh from her neighbor's corpse.

Bill pours [a single drop/a teaspoon] of sterile urine into his colleague's drink.

Cindy engineers the genome of a monkey embryo to make it $[0.001 \% / 0.1 \%]$ more similar to a human.

Michael lets his sister fondle his genitals for [a_split second/thirty seconds].

Liz puts [a gram of/a quarter-pound of] feces into an urn of her grandmother's ashes.

Joe whispers vulgar obscenities into a priest's ear for [an instant/a minute].

Jessica sprays [one particle/a fluid ounce] of cow's blood onto a holy wooden crucifix.

David puts [a single ladybug/10 ladybugs] onto his plate and eats [it/them]. 
Table 1. A set of 32 scenarios for harm and purity violations. Each set has low and high versions of the violations.

\section{Translation and Cultural Adaptation of Materials}

Given that many African countries have a wide variety of languages, we identified the languages that were the lingua franca and/or one widely spoken language where sites were located for adaptations and translations (see Supplementary Table 3: https://osf.io/d73hf/ for list of targeted languages). We translated the study materials into [Arabic, Chichewa, French, Hausa, Igbo, Portuguese, Swahili, and Yoruba].

We adapted our translation and adaptation procedure from the Psychological Science Accelerator's COVID-Rapid project translation process (PSACR; Forscher et al., 2020). We conducted translation and cultural adaptation simultaneously. This ensured that translators stuck to the original meaning as closely as possible, but that the wordings and terminologies also made sense to the different participants. In the first stage, we had two separate forward translation versions. Two translators created materials in the target language based on the English materials, sticking to the original meaning as closely as possible. For cultural adaptation purposes, US-typical names (e.g., Marie, Chris) were replaced with African-typical ones, terminologies (e.g., genome, mercury, graffiti) were replaced with familiar wordings, phrases, or descriptions, while US-based units of measure (e.g., ounce, quarter-pound) were replaced with units of measure relevant to the target country. In the second stage, a language-wise reconciler reviewed the two versions, for cultural appropriateness and produced a final version. Discrepancies between translators were resolved through discussion. In the final stage, a final reviewer proofread the final version, compares the adjudicated version with the source text to ensure the 1) translated text was close as possible to the original text meaning, 2) the words and description were culturally adapted and appropriated in the local context, and 3) that translated text captured the 
theoretical variables present in the original version, and 4) flagged necessary corrections for the reconciler.

\section{Procedure}

Participants signed up for the study online via the recruitment approach determined by that site. Once they started the study, participants were presented with one violation at a time and were asked to rate how wrong, harmful, and impure it is using a slider that ranges from 0 (Not at all) to 100 (Extremely). Each violation was created by choosing either the low or high dose version of a particular item. Participants thus provided 64 sets of ratings of each item on wrongness, harmfulness, and impurity.

As in Rottman's and Young's Study 2, the low-dose and high-dose versions of each item were separated into two blocks of 32 sets of ratings. Thus, although each block contains a mixture of low-dose and high dose violations, a participant did not see the low-dose and high-dose versions of a particular item in the same block. The order of presentation of the two blocks was counterbalanced across participants, and the blocks were separated by a "pen pal task" in which the participant typed a brief transcription of a hand-written letter to someone's pen pal. As in the original studies, we included two attention checks, one in each block that served as the basis for our exclusion criteria. Like the original study, we planned to exclude participants who evaluate the moral wrongness of "A person destroys the entire planet" at below 50, or "A person gives money to a charitable organization" at above 50 on a 0 (not at all) to 100 (extremely) slider scale. In addition to these exclusion criteria, we excluded no consent entries and participants who spent too little time completing the survey. That is, participants spent less than one-third of the median time spent completing the survey. To deal with missing data, we used casewise exclusion. This omits any rows that contain missing data for a particular analysis. At the site level, xx contributing sites aimed to collect data from a minimum of 115 participants, which is $15 \%$ above the CREP-recommended 100 
to allow for data exclusions. Sites stopped collecting data after the 115th participant. We planned to collect data in a six weeks time frame from xxx, $\mathrm{xxx}$ and $\mathrm{xxx}, \mathrm{xxx} 2022$.

[If we reach a minimum of 115 participants from 10 sites before the six-week time frame for data collection].

$\mathrm{Xx}$ out of the $\mathrm{xx}$ contributing sites that completed the CREP procedure collected at least 115 participants within this timeframe, which means we met the sample size required to test the effect. All sites were allowed to continue data collection to finish the six-week timeframe. We decided to include data in the analysis from all sites that completed the CREP procedure even if they collected data from less than 115 participants.

[If we don't have a minimum of 10 sites to collect data from 115 participants by the planned six-week data collection timeframe].

After the six weeks time frame for the data collection, only $\mathrm{xx}$ of the contributing labs that completed the CREP procedure collected data from 115 participants. We needed additional $\mathrm{xx}$ weeks for a minimum of 10 sites to gather at least 115 participants. We stopped all data collection after 10 sites had collected data from 115 participants. We decided to include data from all sites in the analysis that completed the CREP procedure even if they collected data from less than 115 participants.

For exploratory reasons, we included Rottman and Young's six of ten questions: 1) To what extent do you feel that you have close relationships? 2) To what extent do you feel that you are a member of a larger community? 3) How religious are you? 4) I attend a religious service on a regular basis, 5) I participate in community service on a regular basis measured on a slider scale of 0 to 100 (the other exploratory questions we deemed insufficiently relevant for the study in our populations), and one question to which participants can answer "yes" or "no": 6) Have you taken a study on moral judgment before? We did not consider Rottman and Young's exploratory questions on: "Political involvement" and "Following daily 
happenings" because they are not applicable in some African contexts and/or there is no appropriate cultural equivalent or interpretation of these concepts. We did include three open-ended questions that were comparable to the ones we removed that we judged as relevant for these settings: 7) Which religion do you belong to, 8) Are the moral issues we asked about amongst the more important ones for your moral context? If not, which issues are? and 9) Do you have any other comments you would like to share?

To confirm that these exploratory questions are appropriate in African contexts, we asked translators whether the question makes sense within their own cultural context during the translation process. [All the translators considered these questions appropriate in their cultural context/ We removed $\mathrm{xxx}$ and $\mathrm{xxx}$ questions for $\mathrm{xxx}$ and $\mathrm{xxx}$ countries, respectively because the translators considered them inappropriate in their cultural contexts].

At the end of the sets of ratings, participants reported the following demographic information: sex, age, country, country-state, and level of education. The questionnaire is available at: https://osf.io/98j27. We preregistered this current study archived at xxxxx.

\section{Results}

\section{Analysis plan}

We analyzed our data using Linear Mixed Effects Models in the lme4 package (Bates et al., 2015) and obtained $p$-values (with an alpha level set to .05) using the lmerTest package (Kuznetsova et al., 2017) R 4.1.1 version. These models include wrongness judgments as a dependent variable, with fixed effects for domain, dosage, and the interaction between domain and dosage. We used the maximal random effects structure justified by the design (Barr et al., 2013). Our random effects therefore included: at the by-participant level random intercepts and random slopes for domain, dosage, and their interaction; at the by-item level, random intercepts and random slopes for dosage; and at the by-site level, random intercepts 
and random slopes for domain, dosage, and their interaction. In lme4 syntax, this model is fit as follows:

Wrong Domain*Dose + (Domain*Dose $\mid$ ID $)+($ Dose $\mid$ Item $)+($ Domain*Dose $\mid$ Site $)$

where Wrong represents wrongness judgments, Domain is an indicator variable for domain coded $[$ harm $=-.5$, purity $=.5]$, Dose is an indicator variable for dosage coded [low dose $=-.5$, high dose $=.5]$, and ID, Item, and Site are identifiers for specific participants, items, and sites, respectively. This yielded the following fixed effects estimates: $b_{\text {intercep }}, b_{\text {domain }}, b_{\text {dose }}$, $b_{\text {domain } x \text { dose }}$; t-values: $t_{\text {intercept }} t_{\text {domain }}, t_{\text {dose }}, t_{\text {domain } x \text { dose }}$, and their $p$-values. This also yielded the following estimates of the standard deviation of the random intercepts: $s d\left(b_{\text {intercept }}\right)_{I D}$, $s d\left(b_{\text {intercep }}\right)_{\text {Item }}, s d\left(b_{\text {intercept }}\right)_{\text {Site }}$; the following estimates of the standard deviation of the random slopes: $s d\left(b_{\text {Domain }}\right)_{I D}, s d\left(b_{\text {Dose }}\right)_{I D}, s d\left(b_{\text {Domain x Dose }}\right)_{I D}, s d\left(b_{\text {Dose }}\right)_{\text {Item }}, s d\left(b_{\text {Domain }}\right)_{\text {Site, }} s d\left(b_{\text {Dose }}\right)_{\text {Site }}$, $s d\left(b_{\text {Domain x Dose }}\right)_{\text {Site }}$; and finally 13 correlations between random intercepts and slopes (not labeled).

[If at least one of the optimizers yields convergence] To ensure convergence, we checked which optimizers yielded convergence using lme4::allFit. [If none of the optimizers yield convergence] Because none of the optimizers yielded convergence, we trimmed random effects from the model, starting with the highest-order one until it converged (see Brauer \& Curtin, 2018). To establish if our results replicated Rottman and Young, we computed a profile likelihood $95 \%$ confidence interval for the focal interaction coefficient $b_{\text {domain } x \text { dose }}$. We then compared the lower and upper bounds of this confidence interval to 0 and based our interpretation on these comparisons. Our planned interpretations based on where the upper and lower bounds of the confidence interval fall are given in Table 2. 
CI for $b_{\text {domain } x \text { dose }}$

$\begin{array}{lll}\text { Lower bound } & \text { Upper bound } & \text { Interpretation } \\ \text { Any } & >0 & \text { Non-replication } \\ >-9.6 \&<0 & <0 & \text { Weak replication } \\ <-9.6 & <0 \&>-9.6 & \text { Replication } \\ <-9.6 & <-9.6 & \text { Strong replication }\end{array}$

Table 2. Possible interpretations of our results given values we obtain for the $95 \%$ CI for $b_{\text {domain } x \text { dose }}$.

As manipulation checks, we assessed whether participants rated low dose scenarios as less harmful than high dose scenarios, and purity transgressions as less impure than harm transgressions using the same Linear Mixed Effects model as the main analysis. As exploratory analyses, we examined the size of the by-participant, by-item, and by-site random effects. The analysis script is archived at https://osf.io/63xqn/.

\section{Sample and sample demographics}

The dataset was made up of samples from xx African countries ([Egypt, Malawi, Morocco, Mozambique, Nigeria, Tanzania, South Africa, and xxx]; see Supplementary Table

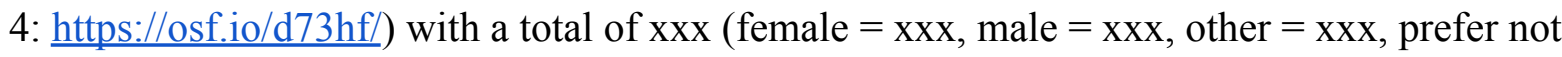
to answer $\left.=\mathrm{xxx} ; M_{\mathrm{age}}=\mathrm{xx}, S D_{\mathrm{age}}=\mathrm{xx}\right)$. The sites collected an average of xxx samples with more than xx sites collecting over 115 participants. Following the exclusion criteria, out of the $\mathrm{xx}$ participants who responded to the questionnaire, we excluded $\mathrm{xx}$ samples comprising 1) those who failed either of the two attention checks $(\mathrm{N}=\mathrm{xx}), 2)$ participants who spent too little completing the survey $(\mathrm{N}=\mathrm{xx})$, and 3$)$ "No consent" entries $(\mathrm{N}=\mathrm{xx})$. We recorded a total exclusion rate of $\mathrm{xx} \%$. We used $\mathrm{xx}$ participants for the main analyses (sample composition of final sample: female $=\mathrm{xxx}$, male $=\mathrm{xxx}$, other $=\mathrm{xxx}$, prefer not to answer $=$ $\left.\mathrm{xxx} ; M_{\mathrm{age}}=\mathrm{xx}, S D_{\mathrm{age}}=\mathrm{xx}\right)$. 


\section{Domain categorizations, and domain and dose analyses: Manipulation checks}

To establish whether the violation acts/scenarios presented in the measure were appropriately classified as harmful or impure, we used the same Linear Mixed Effects Model as in our main analysis to compare participants' ratings of "how harmful a violation is" and "how impure a violation is". Participants rated harm transgressions to be [not/more/less] $\operatorname{harmful}\left(M_{(\text {Harm }) \text { Harmful rating }}=\mathrm{xxx}, s d_{(\text {Harm }) \text { Harmful rating }}=\mathrm{xxx}\right)[$ than/as] purity transgressions $\left(M_{(\text {Purity)Harmful rating }}=\mathrm{xxx}, s d_{(\text {Purity)Harmful rating }}=\mathrm{xxx} ; t(\mathrm{xxx}), p=\mathrm{xxxx}\right)$. They also rated purity transgressions to be $[\mathrm{not} / \mathrm{more} / \mathrm{less}]$ impure $\left(M_{(\text {Purity)Impure rating }}=\mathrm{xxx}, s d_{(\text {Purity)Impure rating }}=\mathrm{xxx}\right)$ [than/as] harm transgressions $\left(M_{(\text {Harm)Impure rating }}=\mathrm{xxx}, s d_{\text {(Harm)Impure rating }}=\mathrm{xxx} ; t(\mathrm{xxx}), p=\mathrm{xxxx}\right.$; $\left.b_{\text {domain }}=\mathrm{xxxx}, 95 \% \mathrm{CI}[\mathrm{xx} ; \mathrm{xx}], p=\mathrm{xxx}\right)$. This suggests that these violations were [rightly/wrongly] categorized.

To check if the transgression severity manipulations (dose; high versus low dosages) influence the wrongness ratings for harm and purity transgressions, we compared the moral wrongness ratings' mean differences and determine whether the t-test p-values are significant $(p<.05)$ for high versus low dosages for both harm and purity transgressions again using the main analysis Linear Mixed Effects Model. [Although] We observed that the mean difference for high dosage $(M($ Harm $)$ High $=\mathrm{xxx})$ and low dosage $($ M(Harm $)$ Low $=\mathrm{xxx})$ for harm transgressions $(M D=\mathrm{xxx} ; s d=\mathrm{xxx} ; t(\mathrm{xx})=\mathrm{xxx}, p=\mathrm{xxxx})$ is [not different/larger/lesser] [from zero compare to/than/as] the mean difference for high dosage $(M($ Purity $)$ High $=\mathrm{xxx})$ and low dosage $(M($ Purity $) L o w=\mathrm{xxx})$ for purity transgressions $(M D=\mathrm{xxx} ; s d=\mathrm{xxx} ; t(\mathrm{xx})=$ $\mathrm{xxx}, p=\mathrm{xxxx}$ ). [However, the $\mathrm{t}$-test $p$-values were not significant/ the $\mathrm{t}$-test $p$-value for low dosage versus high dosage wrongness ratings for harm transgression is significant, while it was not significant purity transgression/ the t-test $p$-value for low dosage versus high dosage wrongness ratings for purity transgression is significant, while it was not significant harm transgression/ the t-test $p$-values were significant]. These findings imply that the dose 
manipulations [check failed for both purity and harm transgressions' wrongness ratings/ checked out for harm transgression wrongness ratings but not for purity transgression/checked out for purity transgression wrongness ratings but not for harm transgression/ checked out for both harm and purity transgressions' wrongness ratings]. [if manipulations fail]

Because the manipulation checks showed that participants' wrongness ratings of how [harmful/ impure/dose severity] [was/were] not significantly different, we concluded that the materials are not applicable to an African context and therefore that Rottman's and Young's findings are not generalizable to Africa, though the "mere-trace" hypothesis may be generalizable with suitable materials. We decided not to proceed to test our hypotheses of establishing if the focal interaction effect of moral judgment of these transgressions exist. However, we conducted two exploratory analyses to 1) check for variation across sites for domain categorization and dose severity and 2) moral issues that our African participants considered important.

\section{Exploratory analysis: exploring sites' random effects on domain categorization and on}

\section{dose severity}

To check if there is a significant difference in sites' estimates for domain categorization and dose severity manipulation checks, we ran a heterogeneity analysis for sites' random effects. Using a reduced model, we explored site random intercepts and slopes for domain and for dose using the lme4 package R 4.1.1 version.

For domain categorization manipulation check; our model reads

$$
\text { Wrong } \sim \text { Domain + (Domain | site) }
$$

For dose severity manipulation check; our model reads

$$
\text { Wrong } \sim \text { Dose }+ \text { (Dose } \mid \text { site) }
$$

We observed that [there is a/ there was no] significant difference in the sites' effect estimate for domain $(t(\mathrm{xxx}), p=\mathrm{xxxx} ; b($ site $)$ domain $=\mathrm{xxxx}, 95 \% \mathrm{CI}[\mathrm{xx} ; \mathrm{xx}], p=\mathrm{xxx}),[\mathrm{and} / \mathrm{while}]$ 
for dose severity $(t(\mathrm{xxx}), p=\mathrm{xxxx} ; b($ site $)$ dose $=\mathrm{xxxx}, 95 \% \mathrm{CI}[\mathrm{xx} ; \mathrm{xx}], p=\mathrm{xxx})$ [was not significant/ is significant]. Indicating that the domains were [rightly/wrongly] categorized [and/while] the dose severity manipulations [were/were not] evident across sites.

\section{Exploratory analysis: Content analysis of moral issues important to Africans}

To examine if the items used in Rottman and Young's studies are applicable to Africans, we analyzed two open-ended exploratory questions directly related to our African participants' moral value focus. We asked participants 1) Are the moral issues we asked about amongst the more important ones for your moral context? If not, which issues are? and 2) Do you have any other comments you would like to share? A content analysis of their responses to these questions showed that African respondents' moral focus is predominantly $[\mathrm{xxx}]$-related such as $\mathrm{xxx}, \mathrm{xxx}$, and $\mathrm{xxx}$ [contrary/similar] to Rottman and Young's harm and purity transgressions-related moral issues. These findings indicated that some of the violation scenarios used in Rottman and Young (e.g., Items xxx, xxx, and xxx) [are not applicable/ applicable] to Africans.

[Interpretation: if findings reveal no variance across sites, and if some of the original items do not apply to Africans]

We concluded that the non-variance observed in the manipulation check estimates for sites could explain why the manipulation failed. Moreso, exploratory of critical moral issues for Africans showed that some of the items used in the original studies were not central to moral issues in Africa.

[Interpretation: if findings show variance across sites]

Although we observed variance in the manipulations for sites, this is not sufficient to explain why the manipulation checks failed. Moreover, some of the original studies' items are not central to African moral issues. There is a need for a comprehensive study to answer these questions. 


\section{Main and interaction effects analyses: Confirming the effect of domain, dose, and domain by dose interaction on moral wrongness judgment}

As in the original studies, we examined the interaction effect of domain by dose on wrongness of these violations to establish in which domain transgression severity significantly counts more.

[If maximal model converges] As planned, we included all of the fixed and random effects in the primary analysis (a maximal model). The model converged and revealed the interaction effect of domain by dose $\left(b_{\text {domain } x \text { dose }}=\mathrm{xxx}, 95 \% \mathrm{CI}[\mathrm{xx} ; \mathrm{xx}], p=\mathrm{xxx}\right)$ was [significant/not significant], meaning that the severity of either harm-based or purity-based violations [did/did not] determine the moral wrongness ratings of these transgressions. Also, the result revealed that the main effect of dose $\left(b_{\text {dose }}=\mathrm{xxxx}, 95 \% \mathrm{CI}[\mathrm{xx} ; \mathrm{xx}], p=\mathrm{xxx}\right)$ was [significant/not significant] while the main effect of domain $\left(b_{\text {domain }}=\mathrm{xxx}, 95 \% \mathrm{CI}[\mathrm{xx} ; \mathrm{xx}], p\right.$ $=\mathrm{xxx}$ ) was [significant/not significant] (see Table 3). The main effect findings indicated that moral wrongness judgment was driven [by what form of violation being perpetrated and severity of the violation/ largely by severity of these violations/ largely by the violation domain].

[if the maximal model doesn't converge] We initially fitted the maximal model to the data, but that model did not converge.

[First, try optimizers in the following order, and the maximal model converges] We first tried different optimizers in the following order: bobyqa, Nelder_Mead, nlminb, nmkbw, L-BFGS-B, optimx.L-BFGS-B, nloptwrap.NLOPT_LN_NELDERMEAD, and nloptwrap.NLOPT_LN_BOBYQA. When we tried [state the specific optimizer] the maximal model converged.

[If none of the optimizers yield convergence] Because none of the optimizers yielded convergence, we sequentially trimmed random slopes from the model until we found one that 
did. We started with the by-site random slopes, then by-item, then by-person. If trimming slopes from a single source of variation did not yield convergence, we trimmed slopes from a pair of each source of variation. If the model still did not yield convergence, we fit a model with random intercepts only. The exact sequence of models that we fit is shown at https://osf.io/quk9f.

The result revealed that the interaction effect of domain by dose $\left(b_{\text {domain } x \text { dose }}=\mathrm{xxx}\right.$, $95 \% \mathrm{CI}[\mathrm{xx} ; \mathrm{xx}], p=\mathrm{xxx}$ ) was [significant/not significant]. Meaning that the severity of either harm-based or purity-based violations [did/did not] determine the moral wrongness ratings of these transgressions. Also, the result revealed that the main effect of dose $\left(b_{\text {dose }}=\right.$ $\mathrm{xxxx}, 95 \% \mathrm{CI}[\mathrm{xx} ; \mathrm{xx}], p=\mathrm{xxx})$ was [significant/not significant] while the main effect of domain $\left(b_{\text {domain }}=\mathrm{xxx}, 95 \% \mathrm{CI}[0.00 ; 0.00], p=\mathrm{xxx}\right)$ was [significant/not significant] (see Table 3). The main effect findings indicated that moral wrongness judgment is driven [by what form of violation being perpetrated and severity of the violation/ largely by severity of these violations/ largely by the violation domain].

\begin{tabular}{|c|c|c|c|c|c|c|c|c|c|c|}
\hline \multicolumn{6}{|c|}{ Fixed effects } & & & \multicolumn{3}{|c|}{ Random effects } \\
\hline \multirow[b]{2}{*}{ Parameter } & \multirow[b]{2}{*}{ Estimate } & \multirow[b]{2}{*}{$S E$} & \multirow[b]{2}{*}{$d f$} & \multirow[b]{2}{*}{$t$-value } & \multirow[b]{2}{*}{$\begin{array}{l}p \text {-val } \\
\text { ue }\end{array}$} & \multicolumn{2}{|c|}{$95 \% \mathrm{CI}$} & \multirow{2}{*}{$\begin{array}{l}\text { Participant } \\
\text { sd }\end{array}$} & \multirow{2}{*}{$\begin{array}{l}\text { Item } \\
s d\end{array}$} & \multirow{2}{*}{$\begin{array}{l}\text { Site } \\
s d\end{array}$} \\
\hline & & & & & & $\begin{array}{l}\text { Lower } \\
\text { Bound }\end{array}$ & $\begin{array}{l}\text { Upper } \\
\text { Bound }\end{array}$ & & & \\
\hline$b_{\text {intercept }}$ & XXXX & $\mathrm{xxxx}$ & $\mathrm{xxxx}$ & $\mathrm{xxxx}$ & $\mathrm{xxxx}$ & $\mathrm{xx}$ & $\mathrm{xx}$ & $\mathrm{xxxx}$ & $\mathrm{xxxx}$ & $\mathrm{xxxx}$ \\
\hline$b_{\text {domain }}$ & $\mathrm{XXXX}$ & $\mathrm{xxxx}$ & $\operatorname{xxxx}$ & $\mathrm{xxxx}$ & $\operatorname{xxxx}$ & $\mathrm{xx}$ & $\mathrm{xx}$ & $\mathrm{xxxx}$ & - & $\mathrm{xxxx}$ \\
\hline$b_{\text {dose }}$ & XXXX & $\mathrm{xxxx}$ & $\mathrm{xxxx}$ & $\mathrm{xxxx}$ & $\operatorname{xxxx}$ & $\mathrm{xx}$ & $\mathrm{xx}$ & $\mathrm{XXXX}$ & $\mathrm{xxxx}$ & $\mathrm{xxxx}$ \\
\hline$b_{\text {domain } x \text { dose }}$ & $\mathrm{XXXX}$ & $\mathrm{XXXX}$ & $\mathrm{xxxx}$ & $\mathrm{xxXx}$ & $\mathrm{xxxx}$ & $\mathrm{xX}$ & $\mathrm{xx}$ & $\mathrm{XxXXX}$ & - & $\operatorname{xxxx}$ \\
\hline
\end{tabular}

Table 3: Linear Mixed Effects Model results for participants' wrongness judgments.

Determining if we replicated Rottman and Young

As reported in Table 3, our estimate for the domain by dose interaction is $b_{\text {domain } x \text { dose }}=$ $\mathrm{xxxx}$, with a $95 \% \mathrm{CI}=[\mathrm{xxx}]$. This estimate and $\mathrm{CI}$ are $[$ describe where the estimate is 
relative to 0 and the Rottman and Young meta-analytic estimate of -9.6]. According to Table 2, this yields an interpretation of [use the table to give an interpretation].

\section{By-participant, by-item, and by-site random effects}

[We will give brief descriptions and interpretations of each random effect in this section. This section is for exploratory purposes and will not bear strongly on our confirmatory analyses].

\section{Discussion}

The discussion will focus on

- manipulation checks (successful or not)

- findings of $b_{\text {domain } x \text { dose }}$, based on the interpretations given in Table 2

- variability check for lab sites random effect for domain, for dose and for their interaction.

- cultural implications of the findings for psychology of Africans

- constraints on generality

- Need for psychology participants and researchers to better represent humanity

- the importance of capacity building for advancing African psychology 


\section{References}

Adetula, A., Forscher, P. S., Basnight-Brown, D., Azouaghe, S., Ouherrou, N., Charyate, A., Hansen, N., Adetula, G. A., \& IJzerman, H. (2021). Synergy Between the Credibility Revolution and Human Development in Africa [Preprint]. AfricArXiv. https://doi.org/10.31730/osf.io/e57bq

Barr, D. J., Levy, R., Scheepers, C., \& Tily, H. J. (2013). Random effects structure for confirmatory hypothesis testing: Keep it maximal. Journal of Memory and Language, 68(3), 255-278. https://doi.org/10.1016/j.jml.2012.11.001

Bates, D. M., Maechler, M., Bolker, B. M., \& Walker, S. (2015). Fitting linear mixed-effects models using lme4. Journal of Statistical SoftwareSoftware, 67(1), 1-48.

Chakroff, A., Dungan, J., \& Young, L. (2013). Correction: Harming ourselves and defiling others: What determines a moral domain? PLoS ONE, 8(9). https://doi.org/10.1371/annotation/38818ce6-1b40-4965-aa64-b7943d2711ed

Forscher, P. S., Paris, B., Primbs, M., \& Coles, N. A. (2020). PSACR: The Psychological Science Accelerator's COVID-19 rapid-response project [Preprint]. PsyArXiv. https://doi.org/10.31234/osf.io/x976j

Green, P., \& MacLeod, C. J. (2016). SIMR: An R package for power analysis of generalized linear mixed models by simulation. Methods in Ecology and Evolution, 7(4), 493-498. https://doi.org/10.1111/2041-210X.12504

Haidt, J. (2007). The new synthesis in moral psychology. Science, 316(5827), 998-1002. https://doi.org/10.1126/science.1137651

Horberg, E. J., Oveis, C., Keltner, D., \& Cohen, A. B. (2009). Disgust and the moralization of purity. Journal of Personality and Social Psychology, 97(6), 963-976. https://doi.org/10.1037/a0017423 
Judd, C. M., Westfall, J., \& Kenny, D. A. (2012). Treating stimuli as a random factor in social psychology: A new and comprehensive solution to a pervasive but largely ignored problem. Journal of Personality and Social Psychology, 103(1), 54-69. https://doi.org/10.1037/a0028347

Kuznetsova, A., Brockhoff, P. B., \& Christensen, R. H. B. (2017). 1merTest package: Tests in linear mixed effects models. Journal of Statistical Software, 82(13), 1-26. https://doi.org/10.18637/jss.v082.i13

Munafò, M. R., Nosek, B. A., Bishop, D. V. M., Button, K. S., Chambers, C. D., Percie du Sert, N., Simonsohn, U., Wagenmakers, E.-J., Ware, J. J., \& Ioannidis, J. P. A. (2017). A manifesto for reproducible science. Nature Human Behaviour, 1(1), 0021. https://doi.org/10.1038/s41562-016-0021

Nsamenang, A. B. (2007). Origins and development of scientific psychology in Afrique Noire. In Psychology: IUPsyS Global Resource (2007th ed.). Psychology Press. http://citeseerx.ist.psu.edu/viewdoc/download?doi=10.1.1.522.4330\&rep=rep1\&type= pdf

Protzko, J., Krosnick, J., Nelson, L. D., Nosek, B. A., Axt, J., Berent, M., Buttrick, N., DeBell, M., Ebersole, C. R., Lundmark, S., MacInnis, B., O’Donnell, M., Perfecto, H., Pustejovsky, J. E., Roeder, S. S., Walleczek, J., \& Schooler, J. (2020). High replicability of newly-discovered social-behavioral findings is achievable [Preprint]. PsyArXiv. https://doi.org/10.31234/osf.io/n2a9x

Roser, M. (2013). Future Population Growth. OurWorldInData.org. https://ourworldindata.org/future-population-growth

Rottman, J., \& Young, L. (2019). Specks of dirt and tons of pain: Dosage distinguishes impurity from harm. Psychological Science, 30(8), 1151-1160. https://doi.org/10.1177/0956797619855382 
Rozin, P., Lowery, L., Imada, S., \& Haidt, J. (1999). The CAD triad hypothesis: A mapping between three moral emotions (contempt, anger, disgust) and three moral codes (community, autonomy, divinity). Journal of Personality and Social Psychology, 76(4), 574-586. https://doi.org/10.1037/0022-3514.76.4.574

Stankov, L., \& Lee, J. (2016). Nastiness, morality and religiosity in 33 nations. Personality and Individual Differences, 99, 56-66. https://doi.org/10.1016/j.paid.2016.04.069

Thalmayer, A. G., Toscanelli, C., \& Arnett, J. J. (2020). The neglected 95\% revisited: Is American psychology becoming less American? American Psychologist. https://doi.org/10.1037/amp0000622

UNESCO. (2021). UNESCO Science Report: The race against time for smarter development; executive summary (SC-2021/WS/7). https://unesdoc.unesco.org/ark:/48223/pf0000377250

Vohs, K., Schmeichel, B., Lohmann, S., Gronau, Q. F., Finley, A. J., whenyoup, I., Wagenmakers, E.-J., \& Albarracín, D. (2021). A multi-Site preregistered paradigmatic test of the ego depletion effect [Preprint]. PsyArXiv. https://doi.org/10.31234/osf.io/e497p

Wagge, J. R., Baciu, C., Banas, K., Nadler, J. T., Schwarz, S., Weisberg, Y., IJzerman, H., Legate, N., \& Grahe, J. (2019). A demonstration of the Collaborative Replication and Education Project: Replication attempts of the red-romance effect. Collabra: Psychology, 5(1), 5. https://doi.org/10.1525/collabra.177

Wagge, J. R., Brandt, M. J., Lazarevic, L. B., Legate, N., Christopherson, C., Wiggins, B., \& Grahe, J. E. (2019). Publishing research with undergraduate students via replication work: The Collaborative Replications and Education Project. Frontiers in Psychology, 10, 247. https://doi.org/10.3389/fpsyg.2019.00247 
Wareham, C. S. (2017). A duty to explore African ethics? Ethical Theory and Moral Practice, 20(4), 857-872. https://doi.org/10.1007/s10677-017-9826-X

Westfall, J., Kenny, D. A., \& Judd, C. M. (2014). Statistical power and optimal design in experiments in which samples of participants respond to samples of stimuli. Journal of Experimental Psychology: General, 143(5), 2020-2045.

https://doi.org/10.1037/xge0000014 